\title{
RNAi-mediated silencing of Trichinella spiralis serpin-type serine protease inhibitors results in a reduction in larval infectivity
}

\author{
Nana Yi, Pengcheng Yu, Lijia Wu, Zhaokun Liu, Jingzhe Guan, Chang Liu, Mingxu Liu and Yixin Lu* (0)
}

\begin{abstract}
Trichinella spiralis serpin-type serine protease inhibitors (TsSPIs) are expressed in adult worms (AW), newborn larvae (NBL) and muscle larvae (ML) of T. spiralis, with the ML stage demonstrating the highest expression level. This study aims to determine TsSPI functions in larval viability and invasion of intestinal epithelial cells in vitro, as well as their development, survival, and fecundity in vivo via RNAi. TsSPI-specific siRNAs and dsRNA were transfected into ML by incubation. The silencing effect of TsSPI transcription and expression was determined using qPCR and western blot, respectively. After incubation in $60 \mathrm{ng} / \mu \mathrm{L}$ dsRNA-TsSPI for 3 days, larval TsSPI mRNA and protein expression levels were reduced by $68.7 \%$ and $68.4 \%(P<0.05)$, respectively. dsRNA-mediated silencing of TsSPI significantly impacted larval invasion into intestinal epithelial cells in vitro but did not affect the survival rate of larvae. After challenge with dsRNA-TsSPI-treated ML, mice exhibited a 56.0\% reduction in intestinal AW burden and $56.9 \%$ reduction in $\mathrm{ML}$ burden $(P<0.05)$, but NBL production of female AW remained the same $(P>0.05)$. Our results revealed that RNAimediated silencing of TSSPI expression in T. spiralis significantly reduced larval infectivity and survival in the host but had no effect on the survival rate and fecundity. Furthermore, TsSPIs have no effect on the growth and reproduction of parasites but may be directly involved in regulating the interaction of T. spiralis and the host. Therefore, TsSPIs are crucial in the process of T. spiralis larval invasion and parasite survival in the host.
\end{abstract}

Keywords: Trichinella spiralis, serpin-type serine protease inhibitors (TsSPIs), RNAi, invasion, infectivity

\section{Introduction}

Trichinellosis is a widespread food-borne parasitic zoonosis whose route of infection is through the ingestion of raw or undercooked meat containing infective muscle larvae (ML) of Trichinella [1]. Approximately 11 million people have been infected by this nematode worldwide $[2,3]$. Trichinellosis is considered an emerging/re-emerging disease [4]. Trichinellosis is not under control in endemic areas because this disease is widely distributed worldwide [5]. Thus, identifying the Trichinella spiralis

${ }^{*}$ Correspondence: luyixin@neau.edu.cn

Laboratory of Animal Common Disease Prevention, College of Veterinary Medicine, Northeast Agricultural University, 59 Mucai Street, Harbin 150030, China
(T. spiralis) invasion-related protein is necessary to prevent the occurrence of trichinellosis.

Trichinella spiralis is an intestinal nematode that infects more than 150 mammalian species [6]. The different developmental phases of T. spiralis occur in a single host. When contaminated meat is ingested, the encapsulation of T. spiralis ML is broken down by gastric juice, ML is liberated in the host's stomach, and bile activates ML to change to intestinal infectious larvae (IIL). IIL penetrate the intestinal epithelium and mature into adult worms (AW) after four moults. AWs deposit newborn larvae (NBL). NBL enter the blood system, invade skeletal muscle, and develop into ML to complete the life cycle $[1,7]$. The evading mechanism has attracted considerable attention from researchers because $T$. spiralis can escape 
the attack of digestive enzymes and the immune system and successfully parasitize and minimize host damage [8]. T. spiralis serine protease inhibitors (TsSPIs), which are the major regulatory antigen in the process of $T$. spiralis host invasion, can inhibit a variety of digestive and immune enzymes of the host [9]. Therefore, investigating the function of TsSPIs is important.

Serine protease inhibitors (SPIs) are a commonly investigated structurally conserved protein superfamily [10]. SPIs are divided into at least 18 families, such as serpin (SPI), Kazal (KaSPI), Kunitz, TAP, and TIL, according to the primary sequence, structural motifs and binding mechanism. Serpin is the most important serine protease inhibitor family [11]. SPIs can control endogenous and exogenous proteolytic activities by inhibiting one or more serine proteases and play important roles in the development, survival, reproduction, inflammation, and apoptosis of animals, plants, parasites, insects and viruses [12, 13]. SPIs are involved not only in the growth and development of parasites, inhibition of blood coagulation, and regulation and suppression of the host immune response $[14,15]$ but also in the early development stage of parasites in the host. Earlier studies showed that TsSPIs can protect parasites from host digestive enzymes by inhibiting their activity $[9,16]$. Thus, TsSPIs may be an important factor in regulating the interaction between $T$. spiralis and the host.

RNA interference (RNAi) was first discovered in the nematode worm Caenorhabditis elegans and has since been widely used to downregulate target molecules [17]. Posttranscriptional gene silencing is a method used to control the reading of mRNA genetic information in organisms. Double-stranded RNA (dsRNA) is degraded into small interfering RNA (siRNA) when dsRNA is transfected into the organism, and then siRNA is guided to the RNA-induced silencing complex (RISC) with Dicer, Argonaute, and RNA-dependent RNA polymerase. siRNA can recognize complementary target mRNA, the antisense siRNA strand in RISC directs binding to corresponding sites of mRNA, and mRNA is degraded by ribonuclease III in RISC [18]. The RNAi technique has been used to investigate the biological function of specific key genes in various helminths, including cathepsin $\mathrm{L}$ and Z-like cysteine proteases in Onchocerca volvulus [19], pyrophosphatase in Ascaris suum [20], beta-tubulin in Haemonchus contortus [21], type V collagen in Schistosoma japonicum [22], enolase in Clonorchis sinensis [23], and paramyosin and Nudix hydrolase in T. spiralis [24, 25].

This study aimed to assess the biological roles of TsSPIs in T. spiralis viability, invasion, development and reproduction via RNAi. TsSPI-specific siRNA or dsRNA was designed to silence TsSPIs in T. spiralis larvae. TsSPI
mRNA and protein expression was analysed to determine the silencing effect. The invasive ability, development and survival of dsRNA-treated larvae in mice were observed in this study.

\section{Materials and methods \\ Parasites and experimental animals}

The T. spiralis T1 strain (ISS3) used in this study was obtained from the Department of Parasitology of Northeast Agricultural University, and its host is a Heilongjiang Xunke pig. BABL/c mice (male, 15-20 g) aged 6-8 weeks were obtained from the Animal Center of Harbin Medical University. Experiments were approved by the Animal Ethics Committee of Harbin Medical University and performed in accordance with animal ethics guidelines and approved protocols (Animal Ethics Committee approval number SYXK [Hei] 2016-007).

\section{Preparation of siRNA}

Full-length cDNA encoding TsSPIs (GenBank accession EU263307.1) was utilized to design siRNA sequences using siDirect version 2.0 [26]. The TsSPI-specific siRNA oligos (Stealth ${ }^{\mathrm{TM}}$ RNAi duplexes) used in this work were chemically synthesized by GenePharma (Shanghai, China). Sequences of the three specific siRNAs and control siRNAs used in this study are listed in Table 1. The same control FAM-labelled siRNA (GenePharma, China) was used to evaluate the transfection efficiency.

\section{Synthesis of dsRNA}

The target DNA fragment of TsSPIs was generated with PCR using TsSPI-specific primers flanked by T7 RNA polymerase promoter sequences based on the sequence regions 247-8121 in dsRNA-TsSPI transcription (Table 2). In addition, a DNA fragment of GFP was generated with PCR for use as a negative control.

PCR products were purified using a $1 \%$ agarose gel and then used to synthesize dsRNA-TsSPI through in vitro

\section{Table 1 The siRNAs used in this study}

\begin{tabular}{lll}
\hline siRNA name & Sense $\left(\mathbf{5}^{\prime} \mathbf{- \mathbf { 3 } ^ { \prime } )}\right.$ & Antisense $\left(\mathbf{5}^{\prime} \mathbf{-} \mathbf{3}^{\prime}\right)$ \\
\hline siRNA153 & GCUGAAUGUGAUGUU & UUUGACAUCACAUU \\
& CAAATT & CAGCTT \\
siRNA479 & CCGUCAACGCAAUUUAUU & AAAUAAAUUGCGUUG \\
& UTT & ACGGTT \\
siRNA986 & CCGAUCGCAUAGUACCCA & AUGGGACUAUGCGA \\
& UTT & UCGGTT \\
Control siRNA & UUCUCCGAACGUGUC & ACGUGACACGUUCGG \\
& ACGUTT & AGAATT \\
\hline & &
\end{tabular}


transcription using a T7 High Yield RNA Transcription Kit (Vazyme, China). The dsRNAs were visualized on a $1 \%$ agarose gel to confirm integrity. The concentration of each dsRNA was determined using a NanoDrop 2000 spectrophotometer (Thermo Scientific, US).

\section{SiRNA or dsRNA Delivery to T. spiralis Worms}

Trichinella spiralis ML were recovered from muscles of infected mice, which were incubated at least 40 days postinfection by digestion with an artificial solution of $1 \%$ pepsin and $1 \% \mathrm{HCl}$ at $37{ }^{\circ} \mathrm{C}$ for $3 \mathrm{~h}$ and washed three times in $0.9 \%$ saline solution $[27,28]$. Incubation methods were used to deliver specific or control siRNA or dsRNA into the larvae. A total of 5,000 ML were suspended in a final volume of $500 \mathrm{ml}$ RPMI 1640 culture medium (HyClone, US) and supplemented with 100 units $/ \mathrm{mL}$ penicillin and $100 \mathrm{mg} / \mathrm{mL}$ streptomycin for incubation. Control siRNA or dsRNA or specific siRNATsSPI or dsRNA-TsSPI were incubated with $2 \mathrm{~mL}$ Lipofectamine 2000 Reagent (Invitrogen, US) for $20 \mathrm{~min}$ before being added to the larvae to a final concentration of $2 \mu \mathrm{M}$ for siRNA and $40 \mathrm{ng} / \mu \mathrm{L}$ for dsRNA. The incubation continued at $37{ }^{\circ} \mathrm{C}$ and $5 \% \mathrm{CO}_{2}$ for 7 days. FAMlabelled control siRNA was used to visualize the uptake of siRNA.

Incubation conditions kept the worms alive for 7 days, when control siRNA or dsRNA were added.

\section{RNA extraction and qPCR analysis of TsSPI mRNA expression}

Total RNA was extracted from siRNA- or dsRNAtreated ML 1-6 days posttreatment with control siRNA or dsRNA or 20, 40, 60 and $80 \mathrm{ng} / \mu \mathrm{L}$ dsRNA-TsSPI or 1, 2 and $3 \mu \mathrm{M}$ siRNA-986 using TRIzol reagent (Invitrogen, US) according to the manufacturer's instructions. Table 2 Gene-specific primers flanked by T7 RNA
polymerase promoter sequences

\begin{tabular}{ll}
\hline Primer & Sense $\left(\mathbf{5}^{\prime} \mathbf{- 3}^{\prime} \mathbf{)}\right.$ \\
\hline TsSPI dsRNA-566 F & GGTCGTTCGTTTCATCGC \\
TsSPI dsRNA-566 R & AGCACCGCTAACTTTGGA \\
TsSPI dsRNA-566 T7 F & $\frac{\text { TAATACGACTCACTATAGGG GGTCGTTCGTTTCAT }}{\text { CGC }}$ \\
TsSPI dsRNA-566T7R & $\frac{\text { TAATACGACTCACTATAGGG AGCACCGCTAAC }}{\text { TTTGGA }}$ \\
dsGFPF & TCCTGGTCGAGCTGGACGG \\
dsGFPT7F & TAATACGACTCACTATAGGG TCCTGGTCGAGCTGG \\
dsGFPR & CGCTTCTCGTTGGGGTCTTTG \\
dsGFPT7R & $\frac{\text { TAATACGACTCACTATAGGG CGCTTCTCGTTGGGG }}{\text { TCTTTG }}$ \\
\hline
\end{tabular}

The underlined portion is the T7 promoter sequence
RNA was visualized with $1 \%$ agarose gel electrophoresis. RNA concentration was measured with a NanoDrop2000 (Thermo Scientific, US). Total RNA was reverse transcribed to first-strand cDNA using HiScript II Q RT SuperMix for qPCR (+gDNAwiper) (Vazyme, China). The following primers were designed for qPCR: TsSPI (forward: AAGGCAATGCGGTCGTT; reverse: CGG CGATAAGGCGAGTA); $T$. spiralis Kazal-type serine protease inhibitor (TsKaSPI), which is a gene with a similar function of verifying the specificity of dsRNA-TsSPI (forward: GATGGATTCTGCTGCCAAG; reverse: CCA AACAACACATTGCTCGT); and GAPDH, which serves as the housekeeping gene (forward: TGGCTTAGCTCC GTTGG; reverse: TTTGGGTTGCCGTTGTA). qPCR was conducted in triplicate using ChamQ Universal SYBR qPCR Master Mix (Vazyme, China) and a 7500 system (ABI, US) to evaluate target gene expression.

Reactions were performed with 40 cycles at $10 \mathrm{~s}$ and $95^{\circ} \mathrm{C}$, as well as $30 \mathrm{~s}$ and $60^{\circ} \mathrm{C}$. TsSPI transcription levels in RNAi-treated larvae were calculated as the percentage relative to the level of untreated larvae. Transcription levels of the target gene in siRNA- or dsRNA-treated worms were normalized by subtracting the expression level of GAPDH and then calculating the quantitative data using the comparative $\mathrm{Ct}\left(2^{-\Delta \Delta \mathrm{Ct}}\right)$ method.

\section{Western blot analysis of TsSPI protein expression}

SiRNA- or dsRNA-treated worms were harvested after 3 days of incubation to observe the effect of siRNA or dsRNA on TsSPI protein expression. Harvested worms were homogenized with liquid nitrogen. RIPA solution was added to the worm fragments (Thermo Scientific, US) and then further homogenized with an ultrasonic disruptor (Scientz, China) (3-s cycle $1 \mathrm{~min}, 40 \%$ power). The supernatant containing soluble crude protein was collected after centrifugation at $5000 \mathrm{rpm}$ for $10 \mathrm{~min}$ at $4{ }^{\circ} \mathrm{C}$. The total protein concentrations were determined with a BCA assay (Wanleibio, China). An equal amount of protein from each treated larval group was separated via SDS-PAGE and subsequently transferred onto nitrocellulose membranes. Membranes were cut into strips, blocked with 5\% (W/V) skim milk in Tris-buffered saline with $0.05 \%$ Tween 20 (TBST), and incubated with mouse anti-TsSPI serum $(1: 200)$ or TsKaSPI $(1: 100)$ at $37{ }^{\circ} \mathrm{C}$ for $2 \mathrm{~h}$. In addition, a mouse antibody against GAPDH $(1: 1,000)$ (Proteintech, US) was used to detect GAPDH expression as a quantitative protein control. HRP-conjugated goat anti-mouse IgG $(1: 8,000)$ was used as the secondary antibody. After washing, strips were treated using an enhanced chemiluminescence (ECL) kit (CWBIO, China). 


\section{Viability of ML treated with dsRNA-TSSPI in vitro}

Larvae treated with dsRNA were cultured in 1640 medium at $37{ }^{\circ} \mathrm{C}$ and $5 \% \mathrm{CO}_{2}$ for 6 days. After incubation for $24 \mathrm{~h}$, the viability of ML was observed under an inverted microscope (Nikon, Japan). Larvae without activity and straight as "C" shapes were considered nonviable but counted as dead with continued inactivity for the next $6 \mathrm{~h}$ at $37^{\circ} \mathrm{C}$. The activity of living ML was characterized by a wriggling motion [29]. The results expressed the number of live larvae within each experiment. The viability of dsRNA-treated larvae was compared with that of control dsRNA-treated and untreated larvae. Each group was independently analysed five times.

\section{Ability of TSSPI-silenced ML to invade intestinal epithelial cells in vitro}

ML were soaked using $60 \mathrm{ng} / \mu \mathrm{l}$ dsRNA-TsSPI or control dsRNA or untreated and cultured for 3 days to assess the effect of TsSPI silencing on the ability of larvae to invade intestinal epithelium cells (Caco-2). ML were then activated into IIL using $5 \%$ goat bile at $37^{\circ} \mathrm{C}$ for $2 \mathrm{~h}$ [30]. Caco-2 cells were grown to confluence in 24-well plates. Each cell monolayer was overlaid with 100 IIL suspended in $0.5 \mathrm{~mL}$ of semisolid medium (RPMI 1640 [HyClone, US] containing $15 \mathrm{mM}$ HEPES and $1.75 \%$ agarose) [31]. The 24-well plate was incubated at $37{ }^{\circ} \mathrm{C}$ in $5 \% \mathrm{CO}_{2}$ for $2 \mathrm{~h}$. IIL invasion into Caco-2 cells was observed under an inverted microscope (Nikon, Japan). The number of penetrating and motile worms in intestinal epithelial cells (IECs) was counted, whereas worms that were still suspended or coiled in semisolid medium were considered nonpenetrated worms [32]. Each group was independently analysed five times.

\section{Development and survival of TsSPI-silenced larvae in mice} Sixty mice were equally divided into three groups to examine the infectivity of TsSPI-silenced larvae. The three groups were orally inoculated with 300 T. spiralis ML soaked in PBS, control dsRNA, and dsRNATsSPI. Ten mice from each group were sacrificed 4 days postinfection (dpi), and AWs were collected from the intestines of sacrificed mice.

The fecundity of recovered female worms was observed after individual incubation in each well of the 24-well plate with culture medium (RPMI 1640 containing 10\% heat-inactivated foetal bovine serum, 100 $\mathrm{U}$ penicillin $/ \mathrm{mL}$ and $100 \mathrm{mg}$ streptomycin $/ \mathrm{mL}$ ) at $37^{\circ} \mathrm{C}$ in $5 \% \mathrm{CO}_{2}$ for $72 \mathrm{~h}$, and the number of NBL produced by each female worm was counted [33]. ML were collected from the 10 remaining mice in each group at 40 dpi by artificial digestion, as previously described. The parasite burden reduction was calculated on the basis of the mean number of intestinal AW and larvae per gram (LPG) of muscles recovered from the dsRNATsSPI group compared with the PBS or control dsRNA group [34, 35].

\section{Statistical analysis}

Statistical analyses were performed using GraphPad Prism 5 expressed as the mean \pm standard deviation (SD). Differences in the relative expression of mRNA and protein, worm burden and fecundity among the groups were analysed using one-way ANOVA. Statistical significance was defined by a $P$ value of $<0.05$.

\section{Results}

SiRNA delivery to T. spiralis ML

Some ML began to moult after incubation with FAMlabelled control siRNA for $12 \mathrm{~h}$ (Figure 1A). Fluorescence staining was observed in ML under fluorescence
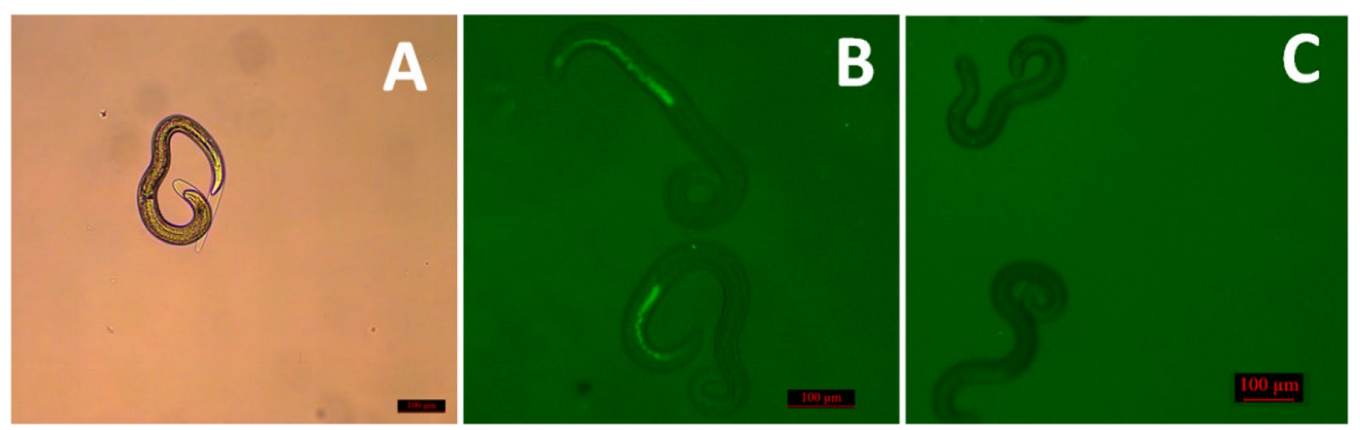

Figure 1 Detection of siRNA delivery to T. spiralis larvae via fluorescence microscopy. Larvae were transfected with FAM-labelled control siRNA by incubation. A Some larvae begin to moult after incubation for $12 \mathrm{~h}$. B Uptake of FAM-labelled siRNA into larvae under the fluorescence microscope. C Absence of fluorescence in untreated larvae. 
microscopy (Figure 1B). However, the absence of fluorescence staining in untreated larvae (Figure $1 \mathrm{C}$ ) demonstrated that siRNA can be efficiently delivered into $T$. spiralis larvae through incubation.
Specific siRNA- or dsRNA-mediated suppression of TsSPI mRNA expression

The qPCR results showed that the TsSPI gene was 52.6\%, $28.1 \%$, and $18.2 \%$ of the relative transcription level compared with the control group in ML treated with 1,2 and $3 \mu \mathrm{M}$ siRNA-986, respectively $(\mathrm{P}<0.05)$ (Figure 2A). After incubation with 20, 40, 60 and $80 \mathrm{ng} / \mu \mathrm{L}$

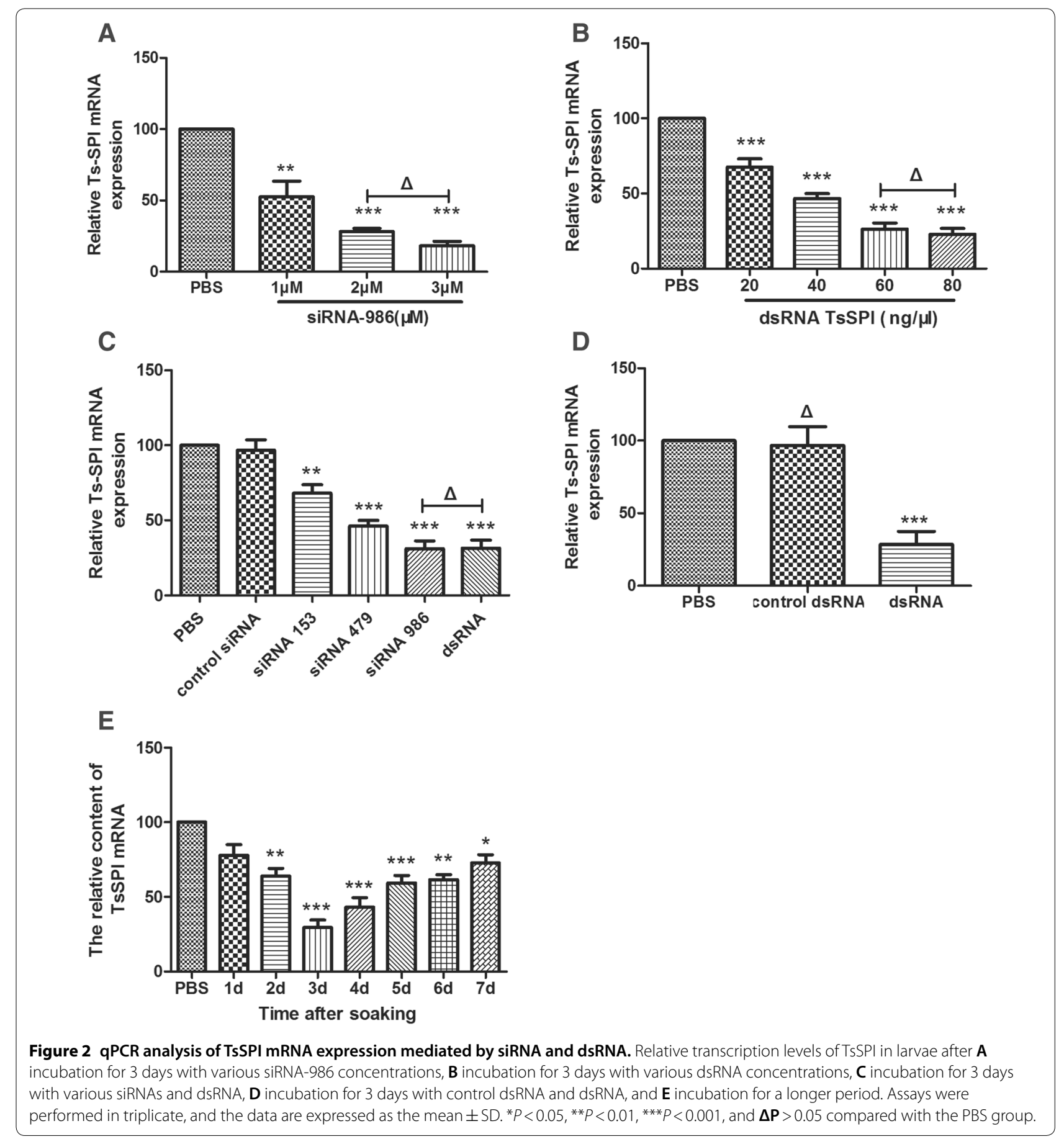


dsRNA-TsSPI for 3 days, the relative transcription levels of the TsSPI gene in treated ML were $67.6 \%, 46.5 \%, 26.4 \%$ and $22.7 \%$ of the relative transcription level compared with untreated $\mathrm{ML}$, respectively $(\mathrm{P}<0.05)$ (Figure $2 \mathrm{~B}$ ). The efficacy of siRNA and dsRNA silencing was dosedependent, although the silencing efficiency achieved with $3 \mu \mathrm{M}$ siRNA or $80 \mathrm{ng} / \mu \mathrm{L}$ dsRNA was the optimal dose, and the difference between 2 and $3 \mu \mathrm{M}$ siRNA or 60 and $80 \mathrm{ng} / \mu \mathrm{L}$ dsRNA-TsSPI was not statistically significant $(\mathrm{P}>0.05)$. Therefore, $2 \mu \mathrm{M}$ siRNA and $60 \mathrm{ng} /$ $\mu \mathrm{L}$ dsRNA-TsSPI were used to optimize the working concentration.

When $2 \mu \mathrm{M}$ siRNA-153, siRNA-479, siRNA-986 or $60 \mathrm{ng} / \mu \mathrm{L}$ dsRNA-TsSPI was transfected into ML for 3 days, the TsSPI gene expression levels in treated larvae were $68.0 \%, 46.0 \%, 31.3 \%$, or $31.6 \%(P<0.05)$ of the relative transcription level compared with untreated larvae, respectively (Figure 2C). The expression level of $T$. spiralis ML was significantly reduced in TsSPI mRNA compared with untreated worms. However, both control siRNA (Figure 2C) and control dsRNA (Figure 2D) clearly had no inhibitory effect on TsSPI gene transcription compared with the PBS group $(\mathrm{P}>0.05)$.

After incubation with $60 \mathrm{ng} / \mu \mathrm{L}$ dsRNA-TsSPI for 1,2 , $3,4,5,6$, and 7 days, the TsSPI gene in treated larvae was $77.9 \%, 63.9 \%, 29.4 \%, 43.2 \%, 59.4 \%, 61.5 \%$ and $72.8 \%$ of the relative transcription level $(\mathrm{P}<0.05)$ compared with untreated larvae, respectively (Figure 2E).

\section{Specific siRNA- or dsRNA-mediated suppression of TsSPI protein expression}

When ML was incubated in $2 \mu \mathrm{M}$ siRNA-153, siRNA479, siRNA-986 or $60 \mathrm{ng} / \mu \mathrm{L}$ dsRNA-TsSPI for 3 days, the expression levels of the TsSPI protein were inhibited by $64.5 \%, 53.6 \%, 32.9 \%$ and $32.4 \%(\mathrm{P}<0.05)$, respectively, compared with the PBS group (Figure 3$)$. However, both the control siRNA (Figure 3) and control dsRNA (Figure 4B) clearly had no inhibitory effect on the expression levels of TsSPI protein compared with the PBS group $(\mathrm{P}>0.05)$.

SiRNA-986 and dsRNA-TsSPI demonstrated the maximum silencing of TsSPI mRNA or protein expression, and no significant difference existed between siRNA986 and dsRNA-TsSPI $(\mathrm{P}>0.05)$. Therefore, $60 \mathrm{ng} / \mu \mathrm{l}$ dsRNA-TsSPI was used to optimize the working concentration for subsequent experiments.

\section{Gene specificity of RNAi induced by dsRNA-TsSPI}

dsRNA-TsSPI $(60 \mathrm{ng} / \mu \mathrm{l})$ was transfected into ML by incubating for 3 days to determine the gene specificity of RNAi induced by dsRNA-TsSPI. The qPCR results showed that the dsRNA-TsSPI-treated group clearly demonstrated no inhibitory effect on the expression

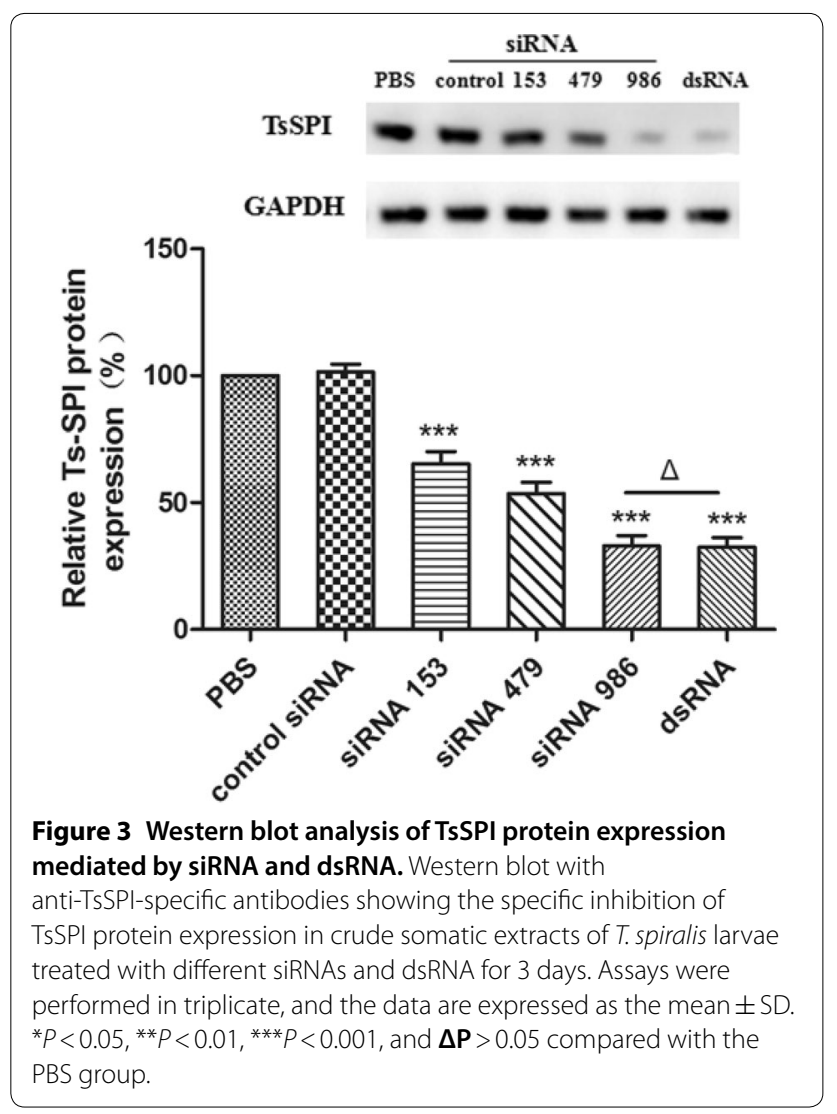

levels of TsKaSPI mRNA compared with the PBS group $(\mathrm{P}>0.05)$ (Figure 4A). Western blot analysis showed that the relative protein expression level of TsSPI was clearly reduced in larvae soaked in dsRNA-TsSPI for 3 days compared with untreated larvae $(\mathrm{P}<0.05)$, but the expression of TsKaSPI protein had no inhibitory effect compared with the PBS group $(\mathrm{P}>0.05)$ (Figure $4 \mathrm{~B})$.

\section{Effect of dsRNA-TsSPI on ML viability in vitro}

When ML was soaked in control dsRNA or dsRNATsSPI for 6 days, the difference was not statistically significant $(\mathrm{P}>0.05)$, although the dsRNA-TsSPI-treated group demonstrated a lower survival rate of larvae than the PBS or control dsRNA groups (Figure 5).

\section{Inhibition of larval invasion into intestinal epithelial cells} by dsRNA-mediated silencing of TsSPIs

When IIL was added to Caco-2 cells and cultured for $2 \mathrm{~h}$, the IIL intruded into Caco- 2 cells and migrated in a monolayer (Figure 6A). The dsRNA-mediated silencing of TsSPIs significantly suppressed larval invasion into the Caco-2 monolayer compared with the control dsRNA group $(\mathrm{P}<0.05)$. However, the difference in inhibiting the invasion of Caco-2 by the larvae soaked in control 

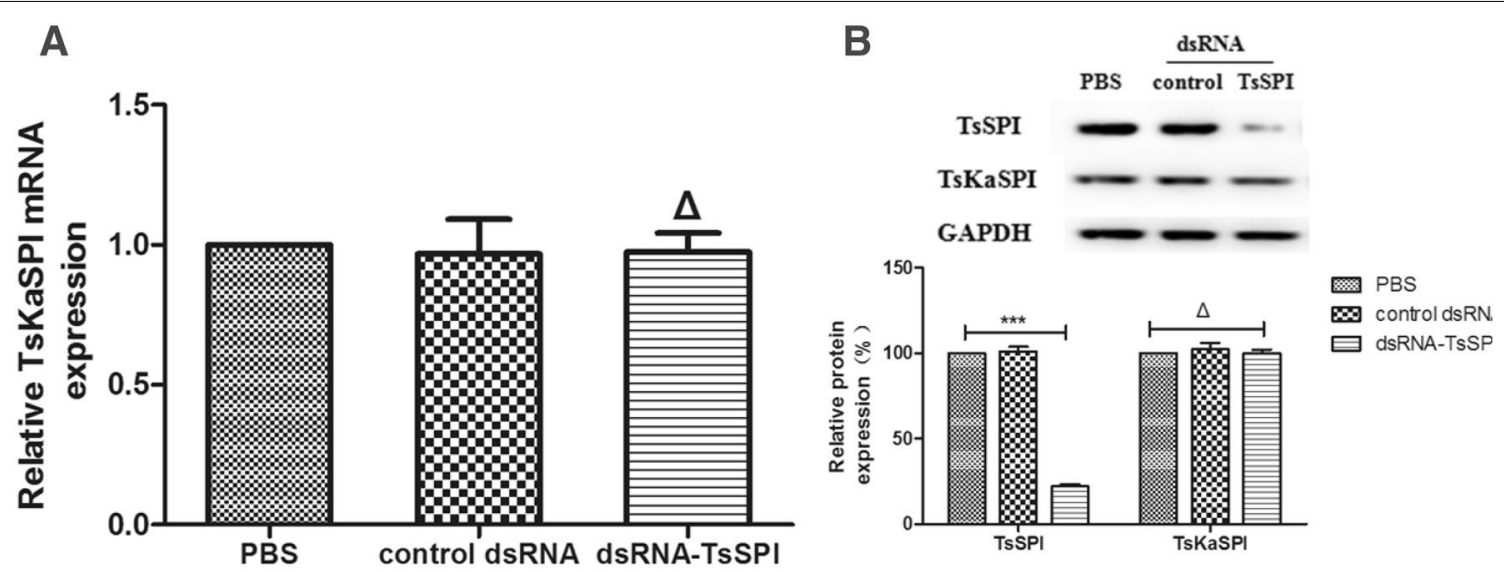

Figure 4 Gene specificity of RNAi induced by dsRNA-TsSPI. A qPCR analysis of relative transcription levels of the TsKaSPI gene in larvae after incubation for 3 days in dsRNA-TsSPI. B Western blot analysis of anti-TsSPI- and anti-TsKaSPI- specific antibodies of relative TsSPI and TsKaSPI protein expression levels after incubation in dsRNA-TsSPI for 3 days. Assays were performed in triplicate, and the data are expressed as the mean \pm SD. ${ }^{*} P<0.05,{ }^{* *} P<0.01,{ }^{* * *} P<0.001$, and $\boldsymbol{\Delta} \mathbf{P}>0.05$ compared with the PBS group.

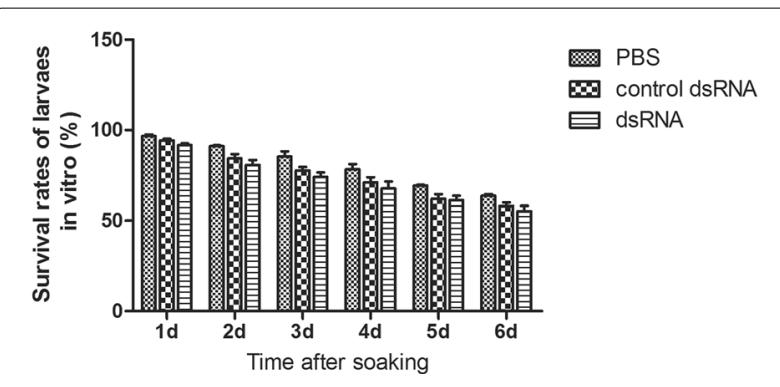

Figure 5 Effect of dsRNA-TsSPI on ML viability in vitro. ML was soaked in control dsRNA or dsRNA-TsSPI for 6 days. The number of live larvae, which were determined to be active by wriggling movements, was counted.
dsRNA and untreated larvae was not statistically significant $(\mathrm{P}>0.05)$ (Figure 6B).

\section{Effect of the in vivo larval infectivity, development, and fecundity via dsRNA-mediated silencing of TSSPI}

Mice inoculated with $T$. spiralis larvae transfected with dsRNA-TsSPI showed statistically significant reductions of $56.0 \%$ and $53.9 \%$ in intestinal AW and ML burden $(\mathrm{P}<0.05)$, respectively, compared with the control dsRNA group. There was no significant reduction in AW and ML burden in mice inoculated with ML transfected using control dsRNA compared with mice inoculated with untreated larvae (Figure 7A, B).
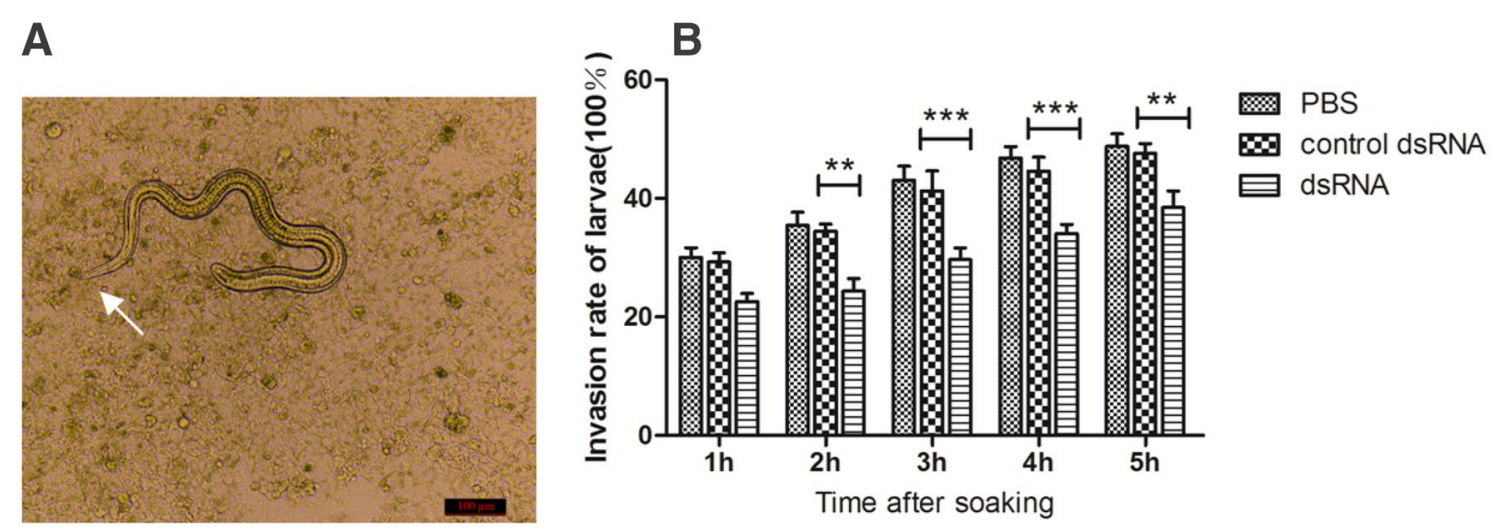

Figure 6 Effect of dsRNA-TsSPI on the capacity of larvae to invade IECs in vitro. A IIL larvae invading Caco-2 and migrating in the monolayer. $\mathbf{B}$ Invasion rate of larvae during a prolonged period after incubation. Assays were performed in triplicate, and the data are expressed as the mean \pm SD. ${ }^{*} P<0.05,{ }^{* *} P<0.01,{ }^{* *} P<0.001$, and $\boldsymbol{\Delta} \mathbf{P}>0.05$ compared with the control dsRNA group. 

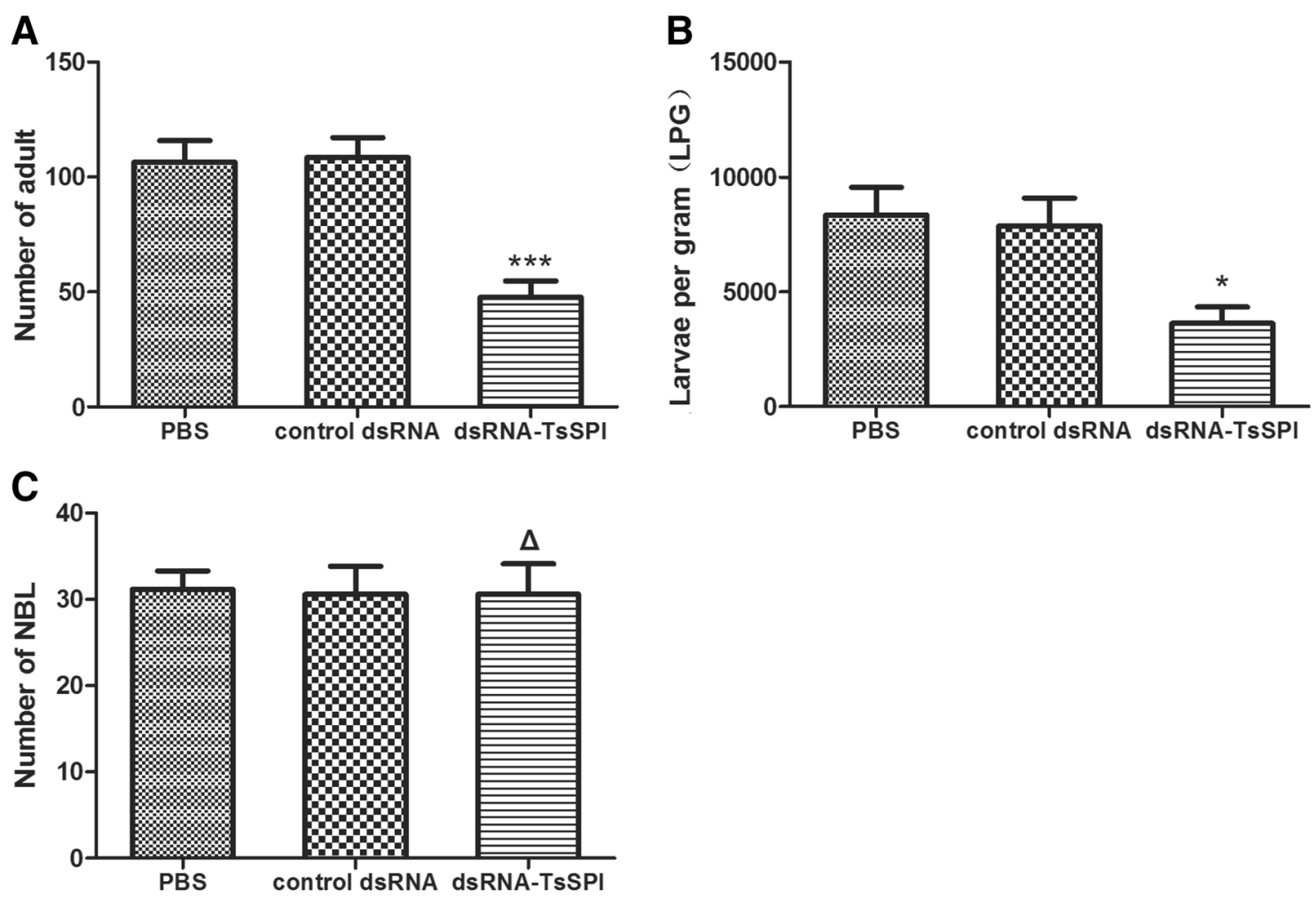

Figure 7 A Number of AWs, B LPG of muscles, and C number of NBL recovered from mice infected with larvae transfected with dsRNATsSPI. Assays were performed in triplicate, and the data are expressed as the mean \pm SD. ${ }^{*} P<0.05,{ }^{* *} P<0.01,{ }^{* *} P<0.001$, and $\boldsymbol{\Delta} \mathbf{P}>0.05$ compared with the control dsRNA group.

The NBL production of female AW from mice inoculated with larvae soaked in dsRNA-TsSPI did not show a significant reduction compared with the control dsRNA group after culturing in vitro for $72 \mathrm{~h}(\mathrm{P}>0.05)$ (Figure 7C).

The results suggested that dsRNA-mediated silencing of TsSPIs significantly impacts larval infectivity and invasion but has no effect on the fecundity of female AW.

\section{Discussion}

Sequencing of the entire genomic $T$. spiralis has been completed, but the functions and biological characteristics of many genes remain unclear [36]. The RNAi technique can effectively investigate $T$. spiralis gene function. RNAi has been widely used in various fields of eukaryotic biology because of its simple operation and strong repeatability in C. elegans [37, 38], especially when organisms are unsuitable for classical genetic methods that directly evaluate gene function. The functions of $T$. spiralis paramyosin (Tspmy) in the viability and growth development of T. spiralis were confirmed for the first time using silencing transcription of Ts-pmy mRNA with RNAi [24]. The new genome editing technique CRISPR-Cas9 has been widely used in recent years to investigate eukaryotes, including protozoa $[39,40]$, but it is difficult to perform in multicellular parasites. Therefore, RNAi was used in this study to evaluate the function of TsSPIs in the life cycle of T. spiralis. The reduction of mRNA and protein expression levels of TsSPIs by $68.4 \%$ and $67.6 \%$, respectively, when dsRNA-TsSPI was effectively delivered into the larvae by incubation indicated that the expression of TsSPI mRNA and protein was significantly inhibited by dsRNA-TsSPI.

In this study, dsRNA-mediated silencing of TsSPIs significantly inhibited IIL invasion into intestinal epithelial cells but did not affect the larval survival rate in vitro. The viability of AW was indirectly affected by the RNAi mediation of ML. Larvae developing into AW must invade the intestinal epithelium [7], but dsRNAmediated silencing of TsSPIs in ML inhibits larvae penetration into the intestinal epithelium and thus hinders the larvae from maturing to AW and depositing NBL in vivo. When mice were inoculated with larvae transfected with dsRNA-TsSPI, the mice exhibited a $56.0 \%$ and $56.9 \%$ reduction of intestinal AW and ML burden, respectively, but the NBL production of the 
same number of female AW remained the same. SPI is a kind of protein superfamily that uses a distinct inhibitory mechanism $[10,41]$. In this study, TsSPIs were expressed in AW, NBL, IIL and ML of T. spiralis but significantly expressed in ML [9]. Another serpintype TsSPI that was highly expressed in NBL can affect the development and invasion of T. spiralis and plays a key role in female fecundity [31, 42, 43]. Therefore, TsSPIs may play a crucial role in the process of the high expression stage. The TsSPI in this study did not affect the survival and fecundity of T. spiralis in vitro but was conducive to ML invasion into intestinal epithelial cells and maturation into AW. The results further demonstrated that TsSPI may not be involved in the growth and reproduction of parasites but is directly involved in regulating the interaction of $T$. spiralis and the host to some extent. Previous studies have shown that TsSPIs can alleviate inflammatory bowel disease, inhibit the host immune response [42, 44, 45], and effectively inhibit the activity of digestion and inflammatory enzymes in the different stages of the $T$. spiralis life cycle and host tissues $[9,46,47]$. TsSPIs can be identified as the major regulatory antigen in the process of T. spiralis host invasion by inhibiting the host's enzyme and immune response.

In conclusion, our results demonstrated that silencing TsSPI expression in T. spiralis significantly reduced larval infectivity and survival in the host, and TsSPIs plays an important role during the process of T. spiralis larval invasion and survival in the host.

\begin{abstract}
Abbreviations
AW: adult worms; dpi: days postinfection; dsRNA: double-stranded RNA; ECL: enhanced chemiluminescence; IECs: intestinal epithelial cells; IIL: intestine infective larvae; LPG: larvae per gram; ML: muscle larvae; NBL: newborn larvae; RISC: RNA-induced silencing complex; RNAi: RNA interference; SD: standard deviation; siRNA: small interfering RNA; SPI: serine protease inhibitor; T. spiralis: Trichinella spiralis; Tspmy: T. spiralis Paramyosin; TsSPI: T. spiralis Serine protease inhibitors.
\end{abstract}

\section{Acknowledgements}

We thank all the staff members who provided laboratory assistance.

\section{Authors' contributions}

YL and NY designed this study. NY, PY, LW, ZL, JG, CL, and ML performed the experiments. YL and NY drafted and revised the manuscript. All authors read and approved the final manuscript.

\section{Funding}

This work was supported by the National Natural Science Foundation of China (31372427), The National Key Research and Development Program of China (2017YFD0501200) and Heilongjiang Province Natural Science Foundation of China (C2016030).

\section{Availability of data and materials}

The datasets used or analysed during the current study are available from the corresponding author on reasonable request.

\section{Ethics approval and consent to participate}

The experiments were approved by the Animal Ethics Committee of Harbin Medical University and were performed in accordance with animal ethics guidelines and approved protocols (Animal Ethics Committee approval number SYXK [Hei] 2016-007).

\section{Consent to publish}

The manuscript has been approved by all authors for publication.

\section{Competing interests}

We declare that we do not have any commercial or associative interest that represents a conflict of interest in connection with the work submitted.

Received: 15 June 2020 Accepted: 22 October 2020

Published online: 23 November 2020

\section{References}

1. Wang N, Bai X, Tang B, Yang Y, Wang X, Zhu H, Luo X, Yan H, Jia H, Liu M et al (2020) Primary characterization of the immune response in pigs infected with Trichinella spiralis. Vet Res 51(1):17

2. Cui J, Wang ZQ, Xu BL (2011) The epidemiology of human trichinellosis in China during 2004-2009. Acta Trop 118(1):1-5

3. Gottstein B, Pozio E, Nockler K (2009) Epidemiology, diagnosis, treatment, and control of trichinellosis. Clin Microbiol Rev 22(1):127-145

4. Murrell KD, Pozio E (2011) Worldwide occurrence and impact of human trichinellosis, 1986-2009. Emerg Infect Dis 17(12):2194-2202

5. Gajadhar AA, Forbes LB (2010) A 10-year wildlife survey of 15 species of Canadian carnivores identifies new hosts or geographic locations for Trichinella genotypes T2, T4, T5, and T6. Vet Parasitol 168(1-2):78-83

6. Ribicich M, Gamble HR, Rosa A, Sommerfelt I, Marquez A, Mira G, Cardillo N, Cattaneo ML, Falzoni E, Franco A (2007) Clinical, haematological, biochemical and economic impacts of Trichinella spiralis infection in pigs. Vet Parasitol 147(3-4):265-270

7. Despommier DD (1998) How does Trichinella spiralis make itself at home? Parasitol Today 14(8):318-323

8. Mitreva M, Jasmer DP (2006) Biology and genome of Trichinella spiralis. WormBook 20:1-21

9. Zhang Z, Mao Y, Li D, Zhang Y, Li W, Jia H, Zheng J, Li L, Lu Y (2016) Highlevel expression and characterization of two serine protease inhibitors from Trichinella spiralis. Vet Parasitol 219:34-39

10. Nagano I, Wu Z, Nakada T, Boonmars T, Takahashi Y (2003) Molecular cloning and characterization of a serine proteinase gene of Trichinella spiralis. J Parasitol 89(1):92-98

11. Gettins PG (2002) Serpin structure, mechanism, and function. Chem Rev 102(12):4751-4804

12. Maizels RM, Gomez-Escobar N, Gregory WF, Murray J, Zang X (2001) Immune evasion genes from filarial nematodes. Int J Parasitol 31(9):889-898

13. Jiravanichpaisal P, Lee BL, Soderhall K (2006) Cell-mediated immunity in arthropods: hematopoiesis, coagulation, melanization and opsonization. Immunobiology 211(4):213-236

14. Huntington JA (2011) Serpin structure, function and dysfunction. J Thromb Haemost 9(Suppl 1):26-34

15. Yenbutr P, Scott AL (1995) Molecular cloning of a serine proteinase inhibitor from Brugia malayi. Infect Immun 63(5):1745-1753

16. Wei J, Gu Y, Yang J, Yang Y, Wang S, Cui S, Zhu X (2011) Identification and characterization of protective epitope of Trichinella spiralis paramyosin. Vaccine 29(17):3162-3168

17. Fire A, Xu S, Montgomery MK, Kostas SA, Driver SE, Mello CC (1998) Potent and specific genetic interference by double-stranded RNA in Caenorhabditis elegans. Nature 391 (6669):806-811

18. Olina AV, Kulbachinskiy AV, Aravin AA, Esyunina DM (2018) Argonaute proteins and mechanisms of RNA interference in eukaryotes and prokaryotes. Biochemistry (Mosc) 83(5):483-497

19. Lustigman S, Zhang J, Liu J, Oksov Y, Hashmi S (2004) RNA interference targeting cathepsin $\mathrm{L}$ and Z-like cysteine proteases of Onchocerca volvulus confirmed their essential function during $\mathrm{L} 3 \mathrm{molting}$. Mol Biochem Parasitol 138(2):165-170 
20. Islam MK, Miyoshi T, Yamada M, Tsuji N (2005) Pyrophosphatase of the roundworm Ascaris suum plays an essential role in the worm's molting and development. Infect Immun 73(4):1995-2004

21. Kotze AC, Bagnall NH (2006) RNA interference in Haemonchus contortus: suppression of beta-tubulin gene expression in L3, L4 and adult worms in vitro. Mol Biochem Parasitol 145(1):101-110

22. Yang Y, Jin Y, Liu P, Shi Y, Cao Y, Liu J, Shi Y, Li H, Lin J (2012) RNAi silencing of type $V$ collagen in Schistosoma japonicum affects parasite morphology, spawning, and hatching. Parasitol Res 111(3):1251-1257

23. Wang X, Chen W, Tian Y, Huang Y, Li X, Yu X (2014) RNAi-mediated silencing of enolase confirms its biological importance in Clonorchis sinensis. Parasitol Res 113(4):1451-1458

24. Chen X, Yang Y, Yang J, Zhang Z, Zhu X (2012) RNAi-mediated silencing of paramyosin expression in Trichinella spiralis results in impaired viability of the parasite. PLoS One 7(11):e49913

25. Wang ZQ, Zhang SB, Jiang P, Liu RD, Long SR, Zhang X, Ren HJ, Cui J (2015) The siRNA-mediated silencing of Trichinella spiralis nudix hydrolase results in reduction of larval infectivity. Parasitol Res 114(9):3551-3557

26. Naito Y, Yoshimura J, Morishita S, Tei K (2009) siDirect 2.0: updated software for designing functional siRNA with reduced seed-dependent off-target effect. BMC Bioinf 10:392

27. Gamble HR, Bessonov AS, Cuperlovic K, Gajadhar AA, van Knapen F, Noeckler K, Schenone H, Zhu X (2000) International Commission on Trichinellosis: recommendations on methods for the control of Trichinella in domestic and wild animals intended for human consumption. Vet Parasitol 93(3-4):393-408

28. Li F, Cui J, Wang ZQ, Jiang P (2010) Sensitivity and optimization of artificial digestion in the inspection of meat for Trichinella spiralis. Foodborne Pathog Dis 7(8):879-885

29. Moskwa B (1999) Trichinella spiralis: in vitro cytotoxicity of peritoneal cells against synchronous newborn larvae of different age. Parasitol Res 85(1):59-63

30. Ren HN, Guo KX, Zhang Y, Sun GG, Liu RD, Jiang P, Zhang X, Wang L, Cui J, Wang ZQ (2018) Molecular characterization of a $31 \mathrm{kDa}$ protein from Trichinella spiralis and its induced immune protection in BALB/C mice. Parasites Vectors 11(1):625

31. Song $Y Y$, Zhang $Y$, Ren HN, Sun GG, Qi X, Yang F, Jiang P, Zhang $X$, Cui J, Wang ZQ (2018) Characterization of a serine protease inhibitor from Trichinella spiralis and its participation in larval invasion of host's intestinal epithelial cells. Parasites Vectors 11(1):499

32. Ren HJ, Cui J, Wang ZQ, Liu RD (2011) Normal mouse intestinal epithelial cells as a model for the in vitro invasion of Trichinella spiralis infective larvae. PLoS One 6(10):e27010

33. Li JF, Guo KX, Qi X, Lei JJ, Han Y, Yan SW, Jiang P, Yu C, Cheng XC, Wang ZQ et al (2018) Protective immunity against Trichinella spiralis in mice elicited by oral vaccination with attenuated Salmonella-delivered TsSP12 DNA. Vet Res 49(1):87

34. Jiang P, Zhang ZF, Wang ZQ, Liu RD, Zhang X, Sun GG, Qi X, Wang L, Cui J (2017) Intraperitoneal inoculation: an atypical route of trichinella spiralis infection. Iran J Parasitol 12(1):130-135
35. Zhang SB, Jiang P, Wang ZQ, Long SR, Liu RD, Zhang X, Yang W, Ren HJ, Cui J (2016) DsRNA-mediated silencing of Nudix hydrolase in Trichinella spiralis inhibits the larval invasion and survival in mice. Exp Parasitol 162:35-42

36. Mitreva M, Jasmer DP, Zarlenga DS, Wang Z, Abubucker S, Martin J, Taylor $C M$, Yin Y, Fulton L, Minx P et al (2011) The draft genome of the parasitic nematode Trichinella spiralis. Nat Genet 43(3):228-235

37. Chuang CF, Meyerowitz EM (2000) Specific and heritable genetic interference by double-stranded RNA in Arabidopsis thaliana. Proc Natl Acad Sci USA 97(9):4985-4990

38. Wianny F, Zernicka-Goetz M (2000) Specific interference with gene function by double-stranded RNA in early mouse development. Nat Cell Biol 2(2):70-75

39. Wiedenheft B, Sternberg SH, Doudna JA (2012) RNA-guided genetic silencing systems in bacteria and archaea. Nature 482(7385):331-338

40. Zheng J, Jia H, Zheng Y (2015) Knockout of leucine aminopeptidase in Toxoplasma gondii using CRISPR/Cas9. Int J Parasitol 45(2-3):141-148

41. Potempa J, Korzus E, Travis J (1994) The serpin superfamily of proteinase inhibitors: structure, function, and regulation. J Biol Chem 269(23):15957-15960

42. Song YY, Zhang Y, Yang D, Ren HN, Sun GG, Jiang P, Liu RD, Zhang X, Cui J, Wang ZQ (2018) The immune protection induced by a serine protease inhibitor from the foodborne parasite Trichinella spiralis. Front Microbiol 9:1544

43. Yang F, Yang DQ, Song YY, Guo KX, Li YL, Long SR, Jiang P, Cui J, Wang ZQ (2019) In vitro silencing of a serine protease inhibitor suppresses Trichinella spiralis invasion, development, and fecundity. Parasitol Res 118(7):2247-2255

44. Xu J, Wu L, Yu P, Liu M, Lu Y (2018) Effect of two recombinant Trichinella spiralis serine protease inhibitors on TNBS-induced experimental colitis of mice. Clin Exp Immunol 194(3):400-413

45. Xu J, Yu P, Wu L, Liu M, Lu Y (2019) Regulatory effect of two Trichinella spiralis serine protease inhibitors on the host's immune system. Sci Rep 9(1):17045

46. Mignogna G, Pascarella S, Wechselberger C, Hinterleitner C, Mollay C, Amiconi G, Barra D, Kreil G (1996) BSTI, a trypsin inhibitor from skin secretions of Bombina bombina related to protease inhibitors of nematodes. Protein Sci 5(2):357-362

47. Yu Y, Cao J, Zhou Y, Zhang H, Zhou J (2013) Isolation and characterization of two novel serpins from the tick Rhipicephalus haemaphysaloides. Ticks Tick Borne Dis 4(4):297-303

\section{Publisher's Note}

Springer Nature remains neutral with regard to jurisdictional claims in published maps and institutional affiliations.

\footnotetext{
Ready to submit your research? Choose BMC and benefit from:

- fast, convenient online submission

- thorough peer review by experienced researchers in your field

- rapid publication on acceptance

- support for research data, including large and complex data types

- gold Open Access which fosters wider collaboration and increased citations

- maximum visibility for your research: over $100 \mathrm{M}$ website views per year
}

At BMC, research is always in progress.

Learn more biomedcentral.com/submissions 